\title{
Recordando aquel 2 de octubre de 1968*
}

\author{
Carlos Encinas Ferrer** : \\ ENES - UNAM León :
}

Han pasado 47 años de aquel miércoles 2 de octubre de 1968 y de la matanza con que se pretendió terminar con el movimiento estudiantil. ¿Quién les iba a decir a los autores de la misma que en lugar de acabar con el movimiento lo que hicieron fue volverlo consciencia histórica y por lo tanto permanente? ¡47 años! Se dicen pronto pero para los que tuvimos más o menos acción en aquellos eventos y que aún sobrevivimos, significa recordarnos jóvenes y compararnos con los adultos mayores que somos hoy en día.

Hace 12 años en un artículo sobre este mismo tema escribía: “...en mi mente se agolpan una gran cantidad de recuerdos. Llevaba, en aquel entonces, dos años trabajando como profesor de asignatura en la Escuela Nacional de Economía de la UNAM y seis meses como Académico de Tiempo adscrito al Centro de Economía Aplicada (CEA) de aquella Institución".

¿Qué más puedo escribir hoy sobre mi tangencial intervención en ese momento histórico?

Sobre lo que entonces escribí, caminaré y pondré algunas otras piedras que pavimenten esta vereda, ya borrosa, de mi memoria.

\section{Recordemos sus antecedentes}

El 22 de marzo de 1968, ocho estudiantes de la Universidad de Nanterre, campus nuevo construido en las afueras de Paris, irrumpieron en la oficina del decano como forma de protesta por el arresto de seis miembros del Comité Nacional de Vietnam. Las autoridades actuaron como estaban acostumbradas, con gran violencia, y así un problema pequeño desató una reacción que nunca se imaginó a los niveles que llegaría y la extensión internacional que alcanzaría.

En los primeros días de mayo las protestas estudiantiles llegaron a las calles y el gobierno francés continuó con su "exitosa" política de represión violenta. Días después las manifestaciones se extendían a todo Paris y de allí saltarían a todo el mundo.

Tras la Cortina de Hierro, en Checoslovaquia, se vivía la llamada Primavera de Praga, y en ese mismo mes de mayo la URSs preparaba la invasión para sofocar aquel movimiento libertario.

En nuestro país se conjuntaron varios sucesos, aparentemente menores, que iban a desatar un movimiento

* Este escrito es una revisión del que escribí con motivo de los 40 años de aquel trágico suceso cuando trabajaba en la Universidad Iberoamericana Puebla. Lo reviso y actualizo anualmente. 
estudiantil de enormes dimensiones y con un impacto histórico que en aquel entonces no preveíamos. Al igual que en Francia y prácticamente en todos los países del mundo, con las presiones demográficas y sociales, la población estudiantil universitaria había crecido en forma geométrica y aunque el estado había dado bastantes fondos para aumentar la oferta educativa, los mismos no eran suficientes para paliar el enorme flujo de estudiantes que no sólo había ya llenado a las universidades, sino que se incrementaba año con año. Estas carencias fueron uno de los motores del movimiento mundial.

El suceso inicial que prendería la mecha del movimiento en nuestro país se dio el lunes 22 de julio con una pelea entre estudiantes de la Vocacional 2, del Instituto Politécnico Nacional, y de la preparatoria particular Isaac Ochoterena incorporada a la UNAM y que tuvo como campo de batalla la Ciudadela de la Ciudad de México y sus alrededores, lugar donde 6 años antes había hecho yo mi servicio militar. En cuestión de minutos se suman refuerzos de la vecina Vocacional 5. Los directivos de la preparatoria Isaac Ochoterena piden ayuda a la policía y llegan cuerpos de granaderos y policías que ejercen una violenta acción que para muchos de los presentes fue excesiva y que alentó la violencia del día siguiente en que porros de las Preparatorias 2 y 6 se suman a los estudiantes de la Ochoterena, contra los estudiantes de las Vocacionales 5 y 2.

¿Dónde estaba la policía aquel martes 23? Bien gracias... de espectadores cuando era obvio que la violencia se iba a desatar. Hoy sabemos que entre los porros había varios infiltrados de la regencia de Corona del Rosal. ${ }^{1}$ Las preguntas que aún surgen son ¿Estuvo orquestada la pasividad policiaca y la violencia de los porros o fue mera coincidencia? ¿La próxima designación del candidato presidencial del PRI y los grupos políticos involucrados en la sucesión enturbiaron todo?

\section{Más leña al fuego}

Aquella misma semana, el viernes 26 de julio, un grupo de estudiantes que conmemoraban la Revolución Cubana y otro más, perteneciente a la Federación Nacional de Estudiantes Técnicos (FNET) que protestaban por la violencia ejercida por la policía contra los estudiantes de las vocacionales 2 y 5 , actuando en manifestaciones separadas, son nuevamente reprimidos violentamente, desatándose una batalla campal en la que hubo numerosos heridos, tanto entre los estudiantes como entre los elementos policiacos. Este era el cemento que

1 Léase lo escrito en http://www.exonline. com.mx/diario/noticia/primera/especiales_nacional/22_de_julio_no_se_olvida/290960 
uniría a los alumnos del Politécnico y de la UNAM en las acciones que a partir del día siguiente desatarían al movimiento estudiantil.

"En aquella época", escribí hace 7 años, "yo era, al igual que muchos otros, un joven idealista recién egresado de una de las escuelas más comprometidas con la justicia social y para mi, lo mismo que para varios otros jóvenes compañeros y compañeras a los que recuerdo con mucho cariño, aquellos sucesos fueron motivo de una actitud decidida en contra de la represión del estado. Nos llenaba de orgullo la postura del entonces rector de nuestra máxima casa de estudios, el Ing. Javier Barrios Sierra, quien nos convocó a una marcha que, recuerdo perfectamente, partió de la Avenida Insurgentes Sur, enfrente de Liverpool, para terminar en el Hemiciclo a Juárez." Hoy la recordamos como "la Marcha del Silencio". Era el viernes 13 de septiembre pero ya muchas cosas habían pasado para esa fecha.

En la madrugada del martes 30 de julio había tenido lugar el artero ataque con bazuca en contra la Preparatoria Número 3 del antiguo edificio de San Ildefonso, antecedente y corazón del que partió la Universidad Nacional en su impresionante crecimiento. La represión y la práctica emboscada sufrida por los estudiantes el 26 de julio los lleva a manifestarse en el Zócalo capitalino la noche del 29. Interviene por primera vez el
Ejército y ante la represión violenta, alumnos del Poli y de la UNAm huyen y se refugian en la Prepa 3. Fuerzas militares los persiguen y tras el "bazukazo" contra la puerta de las instalaciones de la UNAm "la huida de los estudiantes fue cortada por los granaderos y hubo decenas de detenidos", informó el diario Excélsior. Mientras que El Universal, con mayor precisión, publicó que "la enfermería del plantel estaba tinta en sangre. Paredes, pisos, techo, mobiliario, puertas y ventanas, fueron mudos testigos de los sangrientos hechos que culminaron con la participación del instituto armado". 2

Ese mismo día, Ifigenia Martínez, entonces Directora de la Escuela $\mathrm{Na}$ cional de Economía, convocó a sus profesores para que nos organizáramos en un comité permanente que acompañara a los alumnos en lo que ya preveíamos entonces sería un movimiento de no corta duración. Si el gobierno se había decidido a sacar al ejército a la calle y a no negociar en un momento en que aún eran pocos los enconos desatados, ello nos daba una pésima señal que dos meses después veríamos confirmada.

La noche del 30 de julio, en la explanada central de Ciudad Universitaria, una enorme cantidad de universitarios acompañamos a nues-

2 Centro Independiente de Noticias. http:// cinoticias.com/2008/07/30/el-bazukazo-a-lapreparatoria-3/ 
tro Rector, quien izó a media hasta la bandera nacional.

En la primera de nuestras reuniones, y por decisión espontánea de todos los asistentes, el Maestro José Luis Ceceña fue encargado de dirigir el comité de profesores que con carácter permanente estábamos formando. La primera resolución que tomamos aquella noche del 30 de julio fue la de publicar un desplegado con todas nuestras firmas en los principales periódicos. Tuvimos el honor de que ese desplegado del miércoles 31 de julio fuera el primero en aparecer protestando por la agresión contra nuestras Preparatorias 1 y 3 y por el ataque, sangriento ya en ese momento, contra estudiantes tanto de nuestra UNAM como del Politécnico.

Inmediatamente los estudiantes de la UNAM se declararon en huelga y lo mismo hicimos los maestros pero sin dejar de asistir en nuestra obligada jornada laboral a nuestra casa de estudios y trabajo, así como a manifestarnos en cuanta ocasión fuera posible. Recuerdo todavía con claridad cómo entre sesión y sesión del comité, continuábamos con nuestras investigaciones y trabajos.

¿Cuáles fueron las razones que nos motivaban como profesores a organizarnos en un comité que, además, abiertamente mostraba nuestros nombres en los manifiestos que firmábamos, con el riesgo que ello suponía? Deseábamos sobre todo obli- gar a las autoridades a decidirse por el diálogo y a no continuar con la saña violenta que habían mostrado contra los estudiantes la noche del ataque a San Ildefonso y en los días previos.

Mis padres, republicanos españoles exiliados en nuestro país, seguramente se atemorizaron que aquello me involucrara aún más en el movimiento pero, fieles a su pasado de lucha, respetaron mi participación y nunca me dijeron algo al respecto.

Transcurrió más de mes y medio, que a la distancia me parecen unos pocos días por la sensación que la febril actividad en la que nos encontrábamos y la calidad moral de nuestra lucha nos proporcionaba.

El miércoles 18 de septiembre se presenta sumamente confuso en mi memoria. En la mañana de aquel día tenía una gran cantidad de tareas que realizar. Pasado el mediodía y ya de regreso rumbo a mi casa, circulaba por el periférico norte cuando a la altura del Campo Militar Número 1 vi salir del mismo una enorme cantidad de efectivos militares, tanques y camiones de asalto, y enfilar rumbo al sur de la ciudad. Como estábamos acostumbrados ya al despliegue militar a todas horas del día, no me llamó la atención y nunca me imaginé que la autonomía universitaria estaba a punto de ser violentada.

En la tarde de aquel día nos encontrábamos una vez más en la asamblea permanente del Comité de 
Maestros y aproximadamente a las 19:00 horas me retiré de la escuela. Llegué a mi casa 20 minutos después para encontrar a mi madre aterrorizada de que me hubiera sucedido lo que estaba viendo en ese momento en la televisión: las imágenes de la toma de Ciudad Universitaria (CU) en la que mis padres pensaban que aún me encontraba yo.

Me impresionó profundamente ver en la pantalla a nuestra Directora y a todos los compañeros que acaba yo de dejar unos minutos antes, marchando con los brazos sobre la cabeza empujados por soldados que traían la bayoneta calada como si trataran con forajidos.

Hoy sabemos que "decenas de tanques ligeros, vehículos artillados y de transporte, así como una brigada de infantería, el $12^{\circ}$ regimiento de caballería mecanizado, un batallón de fusileros paracaidistas, una compañía del batallón Olimpia, dos compañías del segundo batallón de ingenieros de combate y un batallón de Guardias Presidenciales, en suma, 10 mil efectivos al mando del general Crisóforo Mazón Pineda, se desplegaron en el campus y sus alrededores". ${ }^{3}$ Más de 700 de los 1500 detenidos esa noche en $\mathrm{CU}$, fueron conducidos a la explanada central donde vieron a los soldados arriar la bandera izada a media asta semanas antes por nuestro Rector. Los deteni-

3 http://cinoticias.com/2008/09/18/toma-decu-1968/ dos se pusieron de pie y entonaron el himno nacional hasta que los militares los obligaron nuevamente a sentarse o acostarse boca abajo en el suelo con los brazos tras la nuca.

Era propósito principal de la invasión a Ciudad Universitaria el aprehender a los miembros del Consejo Nacional de Huelga (CNH). Sin embargo un suceso que me fue contado al día siguiente por un compañero que lo presenció, evito que ello se lograra. Resulta que un alumno viajaba en su automóvil, poco antes de las 7 de la noche, rumbo a CU cuando al pasar frente al Monumento a Álvaro Obregón, en Insurgentes Sur, observó la enorme concentración de efectivos militares que en ese momento se ponían en movimiento rumbo a la UNAM. Se imaginó inmediatamente lo que iba a suceder y aceleró rumbo al auditorio de la Facultad de Medicina en el que sesionaba el CNH. Se estacionó y entró al mismo dando gritos para que los miembros del Consejo huyeran. Al principio, me cuentan, nadie le creía y él, desesperado, se subió a las mesas alrededor de las cuales sesionaban los miembros del Comit y con lágrimas en los ojos les imploró que corrieran para salvarse. Esto convenció a los estudiantes de la realidad de lo que venía y sabiendo que el Ejercito entraba desde la Avenida Insurgentes, se dirigieron en dirección opuesta y a través de las rocas y de los arbustos del pedregal de San 
Economía Informa núm. 395 noviembre - diciembre • 2015 - "

Ángel (en aquella época aún no urbanizado), corriendo, saltando y algunos de ellos lastimándose seriamente, pudieron salvarse de su detención y probable muerte por desaparición, cosa muy común en aquel momento.

Se acercaba ya la inauguración de la Olimpiada y se hubiera visto realmente mal que se celebrara la misma en una universidad ocupada por fuerzas militares. Esto hizo que Ciudad Universitaria fuera dejada por las tropas y el jueves 1 de octubre reanudábamos labores "de investigación, administración y, parcialmente, las de difusión cultural. El Consejo Nacional de Huelga decidió mantener la huelga escolar."

Al día siguiente, en la tarde y noche trágica del miércoles 2 de octubre, los que nos encontrábamos laborando en la Escuela Nacional de Economía comenzamos a recibir las noticias de lo que había sucedido en la Plaza de las Tres Culturas, en Tlaltelolco. Algunos de nuestros compañeros universitarios, profesores y estudiantes, presentes en aquella masacre llegaban hasta nosotros aterrorizados y todos los que trabajábamos en el Centro de Economía Aplicada quedamos en gran zozobra ante la ausencia de un joven matrimonio de académicos, compañeros nuestros que vivían en el Edificio Chihuahua, punto central

4 Véase la cronología del movimiento: http://www.terra.com.mx/articulo. aspx?articuloId $=743499$ de la tragedia frente a la Plaza, en la explanada del convento de Santiago Tlaltelolco. Durante esas interminables horas y toda la mañana siguiente no supimos de ellos. Aparecieron finalmente, ya en la tarde del jueves 3 de octubre, aún asustados, después de haberse refugiado desde la noche anterior en casa de unos familiares.

Me es difícil seguir recordando los sucesos que siguieron pero puedo decirles que los días posteriores fueron horribles; en las instalaciones de Ciudad Universitaria recibíamos a alumnos que habían logrado huir de la masacre pero temían regresar a sus casas, llegaban parientes de muchos desaparecidos preguntando por ellos. La propaganda oficial arreció aún más presentando a los universitarios principalmente a los alumnos- como verdaderos delincuentes. Sin embargo, la fuerza moral del movimiento y de cada uno de sus participantes acabó imponiéndose y los autores de aquellas atrocidades fueron repudiados por nuestro pueblo aunque, desgraciadamente, quedaron siempre impunes.

Aquellos sucesos marcaron a nuestra generación - y a nuestra $\mathrm{Na}-$ ción- dejando una profunda huella que nunca podrá borrarse y que nunca permitiremos se olvide. 